\title{
MOTETI JAKOBA GALLUSA \\ IN NAUK O FIGURAH V PRVI POLOVICI 17. STOLETJA
}

\author{
Hermann J. Busch (Mainz)
}

Podrobno preučevanje odnosa med glasbo in besedo $\mathrm{v}$ vokalni glasbi $\mathrm{v}$ času od 16. do 18. stoletja ni mogoče, če ne poznamo nauka o glasbenih figurah. Vse od svojega prvega prikaza, ki ga je napisal leta $1606^{1}$ Joachim Burmeister, pa $\mathrm{v}$ nadaljnjem razvoju do srede 18 . stoletja je ta nauk ustvaril ob povezavi $\mathrm{z}$ retorično umetnostjo pravo bogastvo kompozicijskih tehnik in formul, ki so bile skladateljem pri glasbenem tolmačenju tekstov na voljo tako rekoč kot splošno priznan slovar glasbene govorice. ${ }^{2}$

Teoretiki zgodnjega 17. stoletja, ki obravnavajo $\mathrm{v}$ svojih spisih nauk o figurah, ilustrirajo svoj opis vselej s primeri iz duhovne glasbe XVI. stoletja. Pri tem zavzemajo večinoma prvo mesto dela Lassa. Tu se pokaže, da so že tudi skladatelji tega časa uporabljali takšne formule, medtem ko ni mogla sodobna teorija podati še nikakršnega zaključenega sistema sredstev glasbenega tolmačenja teksta.

Čeprav ni mogel nauk teoretikov nikdar utrditi celotnega področja takšnih sredstev glasbene interpretacije, pa lahko prispeva aplikacija dela takega skladatelja, kot je Jakob Gallus, čigar glasba je posebno tesno povezana s tekstom, ${ }^{3}$ vendarle pomembna spoznanja za tolmačenje njegove glasbene govorice. Predvsem je s primerjavo s sodobno teorijo ovržen sum, da so lahko ustvarili prikazane zveze med tekstom in glasbo interpreti šele pozneje, očitek, ki si ga je poetična hermeneutika starejšega izvora upravičeno nakopala.

Burmeisterjeva definicija za »Ornamentum, sive Figura musica« se glasi: $» . .$. est tractus musicus, tam in Harmonia, quam in Melodia, certa periodo, quae a Clausula initium sumit, \& in Clausulam desinit, circumscriptus, qui a simplici compositionis ratione discedit, \& cum virtute ornatiorem habitum assumit $\&$ induit. $\ll^{4} \mathrm{Tu}$ je že nakazano, da predstavlja figura melodičen ali har-

1 Burmeister J., Musica poetica, Rostock 1606. Faksimilni ponatis, izd. M. Runke, Kassel-Basel 1955. (Documenta Musicologica. Erste Reihe: Druckschriften-Faksimiles. X.).

${ }^{2}$ Unger H. H., Die Beziehungen zwischen Musik und Rhetorik im 16.-18. Jahrhundert, Würzburg 1941, (Musik- und Geistesgeschichte. 4.); Schmitz A., Die Figurenlehre in den theoretischen Werken J. G. Walthers, v Archiv für Musikwissenschaft (AfMw) IX, 1952, str. 79 in dalje.

3 Skladatelji Gallus/Plautzius/Dolar in njihovo delo. Uredil in uvod napisal Dragotin Cvetko. Ljubljana 1963, str. XIV.

4 Burmeister, op. cit., 55. 
monski obrat, ki izstopa iz »preprostega « poteka skladbe in daje takó okrašenemu mestu posebno težo. Da daje tekst povod za uporabo figur, sledi posredno iz razlage: Burmeister utemeljuje, da ne more dati $\mathrm{v}$ svojem delu nikakršnih izpisanih notnih primerov, temveč $\mathrm{k}$ posameznim figuram le odlomke tekstov, kjer so skladatelji uporabili ustrezno figuro in po katerih se lahko ravna tudi začetnik: »Ubi vero necessitas Ornamenti praxin flagitat, ibi officio non erimus defuturi. Exempla item apud authores obvia non damus ad oculum, sed tantum indicamus textum, qui eorum ornatu utitur, \& facimus id saltem, ut tyronem ad crebram resolvendarum cantilenarum exercitationem invitemus \& incitemus; ... Insuper \& hoc addimus, si forte Philomusus sollicitus foret scire, quando \& quo loco Harmoniae flosculis harum Figurarum sint exornandae, \& quando ea adhibendae, ibi Philomusus textum alicujus Harmoniae, cujusdam autoris, \& praesertim, quae alicujus ornamenti cultum \& ornatum induisse videtur, probe consideret, arbitreturque sibi similem textum eadem figura esse exornandum quo ille alterius Artificis textus est exornatum. $\aleph^{5}$ C̆e potem Burmeister, kakor tudi poznejši teoretiki, ${ }^{6}$ pri opisu posameznih figur izrecno ne označuje vselej njihove slikovitosti ali vsebine afekta, pa izhajata ta dovolj jasno iz navedenih primerov teksta.

Figure lahko razdelimo $\mathrm{v}$ dve glavni skupini harmonskih in melodičnih figur. Tu naj razumemo pod »harmonskimi« figurami v širšem smislu vse takšne tvorbe, ki zadevajo večglasni kompozicijski kompleks v njegovi strukturi, podobno kot je to napravil, čeprav nekoliko nedosledno, tudi Burmeister v »Ornamenta Melodiae« in »Ornamenta Harmoniae«.

Kot prvo harmonsko figuro navaja Burmeister ${ }^{7}$ fugo realis, običajno oblikovanje posameznih pasusov motetne forme, kjer vstopajo posamezni glasovi imitirano. Tesnejšo zvezo $\mathrm{s}$ tekstom ima ta sicer splošno razširjena tehnika le, če nastopi očitno sredi drugače homofonega stavka in tako »a simplici compositionis ratione discedit«. Takšen nastop imitacije, ki je vezana s tekstom, najdemo pri Gallusu na primer v motetu 3, XVII $(40,48),{ }^{8}$ pri besedah »vivet in aeternum «, ki se stalno ponavljajo v imitaciji in smiselno ponazarjajo »večno življenje«. V motetu 2, XXXVIII $(30,100)$ pa izzove tekst »praecedet vos in Galilaem« fugiran način obdelave: medtem ko deklamirajo soprani, alt in tenor II v akordskem stavku besedo »dixit«, vstopi tenor I že s tekstom »praecedet«. Za njim imitacijsko slede še drugi glasovi. ${ }^{9}$ Podobne primere najdemo $\mathrm{v}$ motetu 1 , LXXXVII $(24,73)$ pri »persequimini« in motetu 4 , LII $(51 / 52,27)$ pri »imitati

5 Ibid., 56.

6 Burmeisterju sledita neposredno: Johannes Nucius, Musices Poeticae sive de compositione cantus praeceptiones, Neisse 1613, pogl. VII in Joachim Thuringus, Opusculum bipartitum, Berlin 1624, ki se le-temu v marsičem pridružuje. Prim. Feldmann F., Das »Opusculum bipartitum« des J. Thuringus (1625), besonders in seinen Beziehungen zu $J$. Nucius (1613), AfMw XV, 1958, 123 in dalje.

7 Op. cit., 55.

${ }^{8}$ Zaradi poenostavljenja so navedeni moteti iz zbirke »Opus Musicum« po štetju originalne izdaje; arabska številka označuje število zvezka, rimska pa motet, v oklepaju sledi številka zvezka in strani nove izdaje v Denkmäler der Tonkunst in Österreich (DTÖ).

${ }^{2} \mathrm{~V}$ podobni tekstovni zvezi tudi v 2 , XXXI $(30,49)$. Isti pasus teksta je prav tako tolmačen v Lassovi uglasbitvi. (Sämtliche Werke, izd. F. X. Haberl in A. Sandberger, Leipzig 1894, zv. XIII, 16. Nadalje je ta izdaja citirana kot GA z navedbo številke zvezka in strani.) 
sunt«. Stranski obliki metalepsis (fuga $\mathrm{z}$ dvema temama, pri kateri je druga tema podložena nadaljevanju začetnega teksta) in apocope (svobodno oblikovana imitacija, ki ni v vseh glasovih strogo izpeljana), ki ju opisuje Burmeister $\mathrm{v}$ zvezi s fugo realis, pa sta le kompozicijski tehniki, ki v primerjavi s fugo realis ne odpirata novih možnosti tolmačenja teksta. Ti očitno spadata $\mathrm{k}$ tistim figuram, ki so dodane $\mathrm{k}$ nauku o kompoziciji le zaradi njihovega kompozicijskega oblikovanja in to brez zveze $\mathrm{z}$ določeno vsebino teksta. Pač pa se pogosto uporablja hypallage, protifuga, za prikaz nasprotja. V exordiumu moteta »Peccantem me quotidie« $1, \mathrm{XC}(24,81)$ sledi Gallus povsem očitno vzoru Lassa, ki v svoji uglasbitvi istega teksta (GA I, 159) uporabi prav tako protifugo kot slikovni izraz »nasprotja« greha do božje volje.

Poleg imitacijskega načina je tudi akordični stavek sredstvo tolmačenja teksta; takšna mesta $v$ imitacijsko ali ritmično komplementarno oblikovanem stavku označuje nauk o figurah kot noema: »... est talis harmoniae affectio, cujus habitus voces conjunctas habet in eadem sonorum quantitate.«10 Razen akordskega stavka navadno označuje noematične figure tudi glede na okolje zmanjšana hitrost deklamacije, tako da te izstopajo iz zveze $\mathrm{v}$ dveh ozirih. Tako predstavljajo važno sredstvo za podčrtavanje nekega posebno pomembnega dela teksta. Ta figura izzove $\mathrm{v}$ nasprotju $\mathrm{z}$ imitacijo, ki ponazarja tekst $\mathrm{v}$ sliki, afekt, ki naj posebaj obrača pozornost poslušalca na ustrezni smisel teksta: »... aures, imo \& pectora suaviter afficiens \& mirifice demolcens. «11 Predvsem ima noema svoje mesto pri vzklikih in prošnjah. Posebno nazoren primer nudi $1, \mathrm{I}(12,7)$, kjer zakliče prvi zbor svoj široko deklamirani »Ecce« $v$ razgibano melizmatiko drugega zbora. Nadalje ugotovimo takšen emfatičen poudarek v 3, XLII $(40,133)$ pri »exaudi Domine« in v $3, \mathrm{XXV}(40,114)$ pri »exaudi preces«. Zlasti učinkovita pa je noema, če nastopi takoj na začetku sicer strogo imitacijsko izpeljanega moteta. Drugače je exordium tradicionalno mesto za fugo realis oziroma njene stranske oblike, medtem ko je noematično oblikovanje izjema, ki jo upravičuje le smisel teksta. »Noema locum quandoque in Exordio obtinet. Utinam, quam saepe hoc fit, tam saepe ea textui inserviat sententioso...«12 Gallus uporablja to sredstvo med drugim v motetu »Omnes de Saba venient « 1, LV $(12,163)$. Besedo »Omnes« izvaja dvakrat v dolgih notnih vrednostih vseh (!) pet glasov, nakar šele začenja $\mathrm{z}$ »de Saba venient« fugirana obdelava. Podoben primer nudi tudi 4, CXIII $(51 / 52,162)$.

Dosti pogosteje kot enostavna noema nastopata njeni ponavljalni obliki analepsis (»Noematis repetitio \& duplicatio) ${ }^{13}$ in auxesis (»quando Harmonia sub uno eodem textu semel, bis... repetito, conjunctis solis Concordantibus, crescit \& insurgit.«14). Primer za obe obliki vsebuje »Ave Maria« 4, LXXIII $(51 / 52,79)$ pri »et benedictus fructus ventris tui«. To mesto se izvaja najprej kot analepsis dvakrat štiriglasno, pri drugi ponovitvi pa je stopnjevano kot auxesis do petglasja. Ustrezna figura $\mathrm{v}$ mnogozbornih kompozicijah je anaploce: »... est in Harmoniis ex Octo praesertim vocibus, \& duobus choris constantibus prope clausulam vel in ipsa etiam Clausula Harmoniae unius Chori

10 Burmeister, op. cit., 59.

11 Ibid., 59.

12 Ibid., 59.

13 Ibid.

14 Ibid., 72. 
in altero replicatio, repetitione ad binas ternasve vices inculcata.«15 Značilno je, da razlaga Burmeister to figuro na primeru iz Gallusovega Opus Musicum. Iz moteta »Quam dilecta tabernacula tua« 3 , XXVIII $(40,83)$ citira mesto »qui sperat in te«, kjer je izveden kratek, pomemben retorični pasus večkrat po shemi:

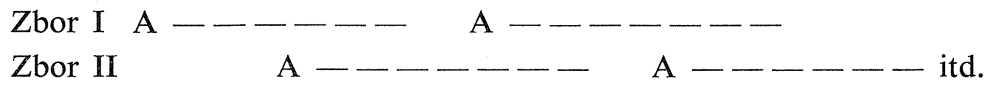

Nadaljnji primeri so pri Gallusovih mnogozbornih skladbah zelo številni: 1 , XXXVI $(12,103)$ pri »laudate«; XXXIV $(12,91)$ pri »dispersit« in »fremet «. Že sodobni teoriji so torej veljala prav Gallusova dela za šolske primere te tehnike mnogozbornega načina. Johannes Magirus, sodobnik Burmeistra, označuje isto figuro anaploce kot »fugo«. Tak pomen izraza fuga poleg kompozicijsko tehničnega pojma imitacije in fuge »alio nempe sensu« 16 je seveda pri Magirusu redek in je ostal doslej še nezapažen: »Habent etiam Fugae suam singularem in clausulis gratiam, quando scilicet eaedem clausulae in diversis Choris repetuntur.«17 Vsi njegovi primeri za to figuro so vzeti iz Gallusa: »Alleluja« iz 2, XXXI $(30,49)$, »in voce tubae« iz 2 , XXXVI $(30,94)$ in neko mesto iz izgubljenega moteta »Ascendit Deus in jubilo«.

Med harmonskimi figurami $v$ ožjem smislu navaja Burmeister najprej disonančno figuro syncope, ki jo razlikuje od sinkope $\mathrm{z}$ zadržkom $\mathrm{v}$ discantni klauzuli. Njena uporaba $v$ zvezi $z$ večglasno klauzulo je bila seveda tako običajna, da je ta imela ne glede na tekstovno zvezo svoje stalno mesto kot sredstvo umetnejše zasnovanega zaključka: $\gg$ Differt autem hoc Ornamentum a Clausula, quod sonus in Clausula tertius, sit idem, qui fuit ejus primus, videlicet ille contractus: in hoc vero Ornamento tertius a secundo, ut secundus a primo syncopato isto, declinet.«18 V zvezi s figuro pleonasmus nastopa syncope skupno $\mathrm{z}$ nadaljnjo figuro, ki se imenuje symblema. Tu gre za prehod v vrednosti minime: »suavitate quadam et energia delectat afficiatve. $\ll 19$

Primer za takšno figuro pleonazma, ki nastopi s svojim disonančnim bogastvom vselej pri posebno afektivnem tekstu, nudi zaključek moteta $\gg \mathrm{O}$ vos omnes« 2, IV $(24,139)$. (Glej notni primer na str. 44).

Nadaljnji primer za syncopo vsebuje uglasbitev lamentacije 2, XVII $(30,1)$. $\mathrm{Tu}$ nastopi posebna zaostritev zaradi trenja zadržanega tona $\mathrm{z}$ neposredno sosednim tonom razveza (takt 25 ). (Glej prvi notni primer na str. 45).

V 2, XXVI $(30,28)$ srečamo celo verigo sinkopiranih zadržkov, a na zaključku je spet symblema (takt 56 in dalje). (Glej drugi notni primer na str. 45).

Nadaljnji primeri: 1, LXVIII $(24,13)$ pri »luctum«; $1, \mathrm{XCV}(24,97) »$ in vocem flentium « etc.

$\mathrm{K}$ posebnim harmonskim tvorbam spada pri Gallusu predvsem uporaba trizvoka na $\mathrm{B} v$ netransponiranih oziroma na Es $\mathrm{v}$ transponiranih tonskih na-

15 Ibid., 72.

16 Janowka Th. B., Clavis ad thesaurum magnae artis musicae, Praga 1701, 56. Tu je s »Fuga, alio nempe sensu« označena figura, ki je v hitrem gibanju enega ali večih glasov in ki služi za slikoviti prikaz hitrega gibanja.

17 Magirus J., Artis Musicae legibus logicis methodice informatae libri duo, Braunschweig $1611,117$.

18 Burmeister J., op. cit., 61.

19 Burmeister J., Hypomnetatum Musicae poeticae, Rostock 1599, pog1. XII. 

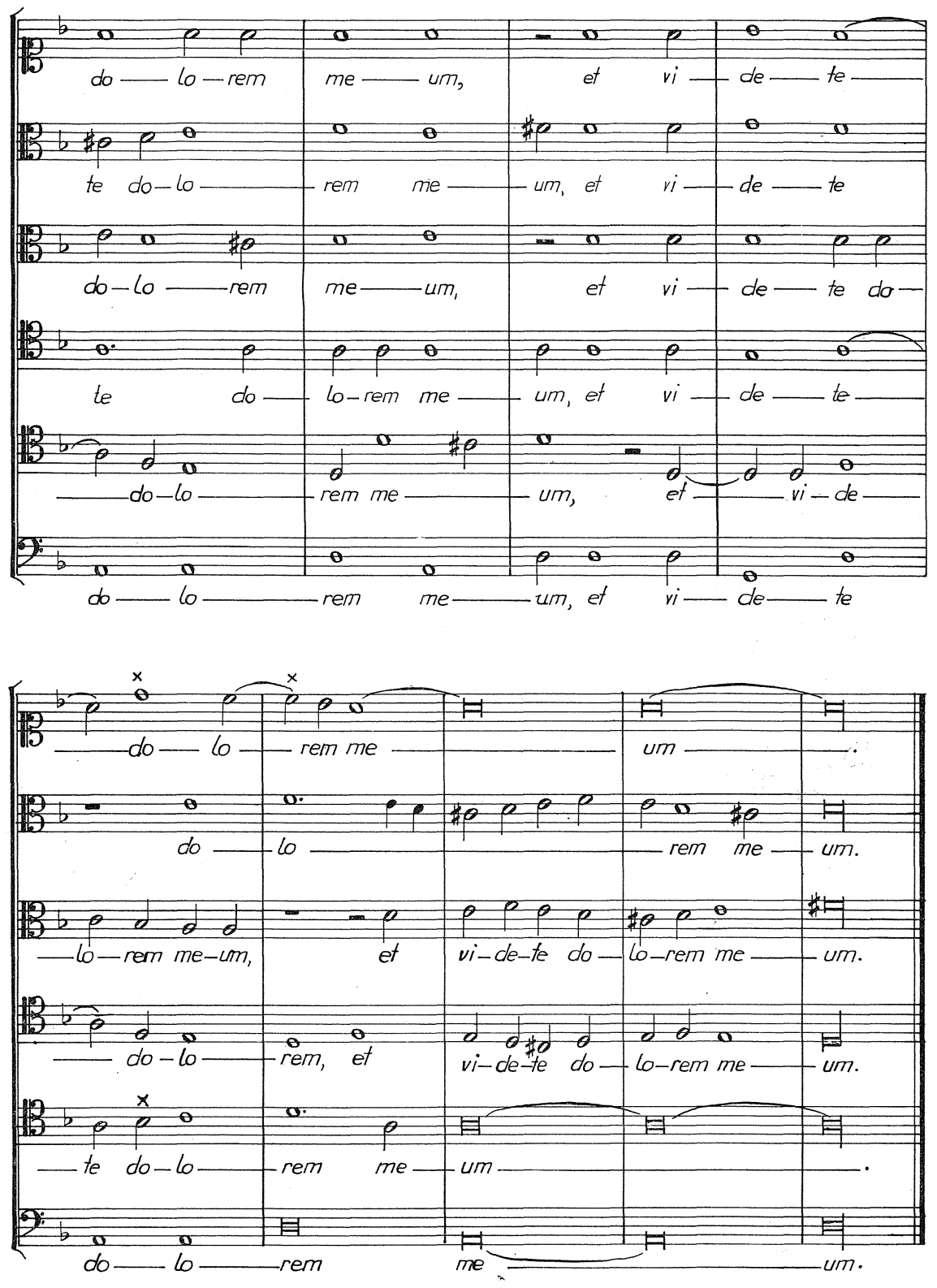

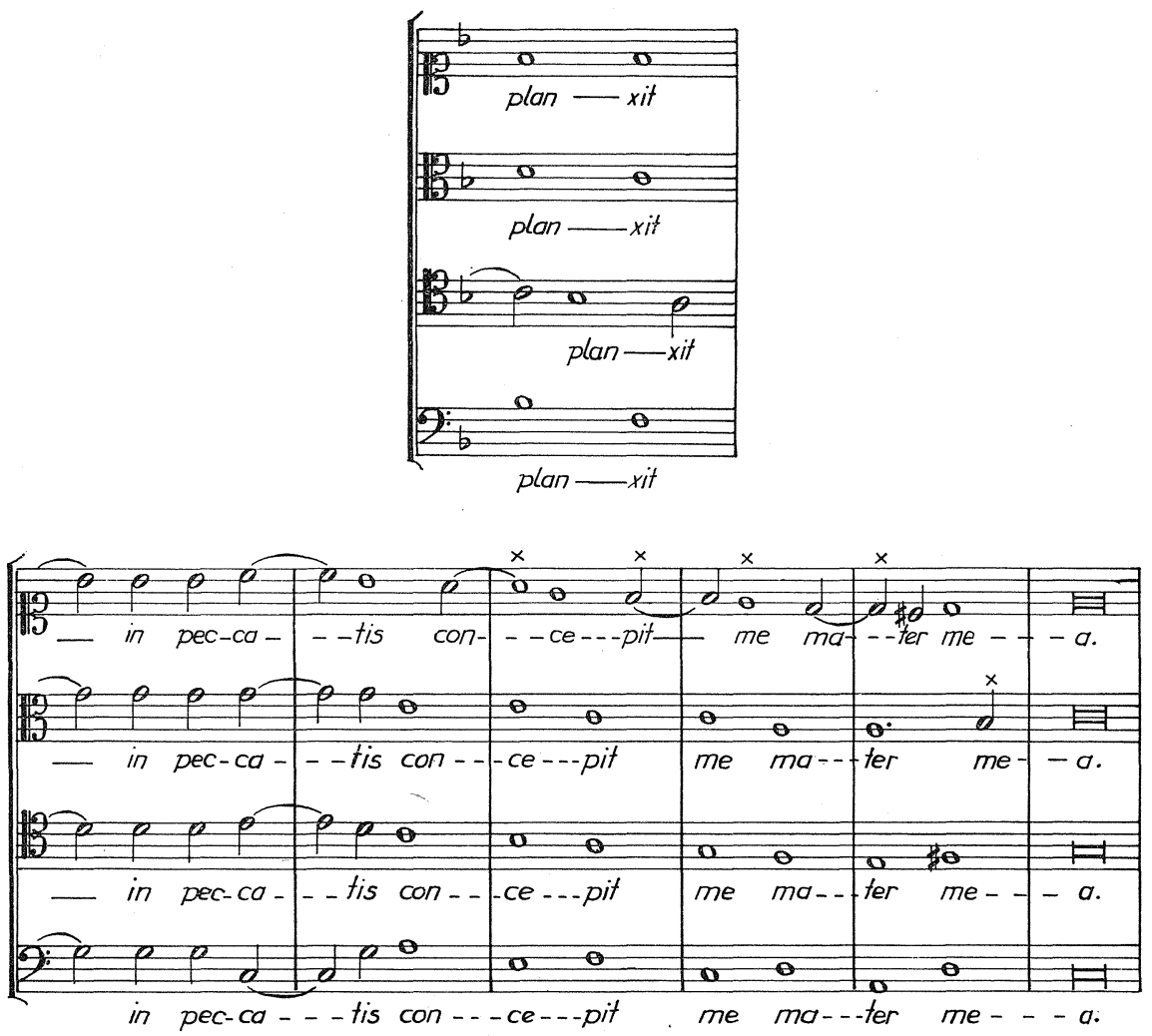

činih, po Riemannovem sistemu torej »dvojna subdominanta.«20 Skoro vedno se pojavijo take tvorbe na afektivno posebno poudarjenih mestih teksta. Takšno uporabo trizvoka na B lahko ugotovimo že pri Lassu21, Burmeister pa omenja celo vrsto takšnih primerov pod figuro pathopoeia. "...est figura apta ad affectus creandos, quod fit, quando semitonia carmini inserentur, quae nec ad Modum carminis, nec ad Genus pertinent...«22 Gallus uporablja takšne tvorbe dvakratno. Najprej za deklamatorični poudarek smiselnega akcenta kot npr. v 2, L $(30,133)$ (takt 13 in dalje):

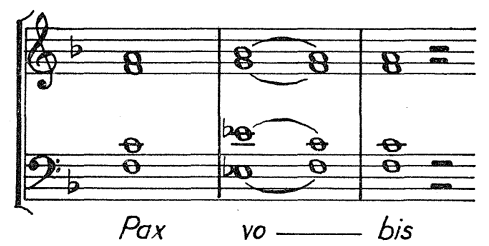

.20 Cvetko D., Jacobus Gallus Carniolus, Ljubljana 1965, 272.

21 Prim. Reichert G., Kirchentonart als Formfaktor in der mehrstimmigen Musik des 15. und 16. Jahrhunderts, Musikforschung IV, 1951, 45.

22 Burmeister, Musica poetica ..., 61. 
Nadaljnji primeri: 3, XXVIII (40, 83) II. pars: »exaudi«: 2, XXXVI $(30,94)$ »omnem terram«. Sem spada tudi mesto pri »altissimi« v 1, XXIV $(12,59)$, ki ga Ambros v svoji podcenjujoči oznaki Gallusove harmonike posebno graja kot »harmonski sunek «. ${ }^{23}$ To harmonsko figuro najdemo nadalje pri posebno afektivnih besedah, kot npr. v 3, XLIX $(40,152)$ (takt 3):

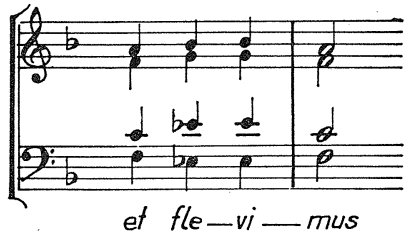

Tu lahko sestavimo kar cel seznam značilnih izrazov, ki jih Gallus podčrtava v vsebini njihovega afekta:

$\begin{array}{lll}\text { suaviter } & 1, \text { XVIII } & (12,48) \\ \text { melifluus } & 1, \text { XXVIII } & (12,65) \\ \text { admirabile } & 1, \text { XXXIII } & (12,88) \\ \text { gemitus } & \text { ibid } & \\ \text { moriri } & 3, \text { XII } & (40,37) \\ \text { tristis } & 3, \text { LIII } & (40,160) \\ \text { tribulatio } & 4, \text { XI } & (48,50) \\ \text { amor } & 4, \text { CXXXVIII } & (51 / 52,210)\end{array}$

Definicija figure hypotyposis: \...est illud ornamentum, quo textus significatio ita deumbratur, ut ea, quae textui subsunt $\&$ animam vitamque non habent, vita esse praedita, videantur.« 24 je edina, ki dá pogrešati kompozicijsko tehnično fiksiranje. Navedeni primeri kažejo, da so s tem pojmom zajete najrazličnejše oblike tolmačenja afekta kakor tudi ponazarjanja teksta. Pri Burmeistru najdemo med drugim citiran zaključni del moteta »Sicut Mater« Orlanda Lassa (GA VII, 97), kjer se pri tekstu »Et gaudebit cor vestrum« spremeni dvodelni $\mathrm{v}$ tridelni ritem. Tudi $\mathrm{v}$ večini primerov, kjer uporabi Gallus tridobni takt, ${ }^{25}$ daje za to povod radostni afekt teksta:

$\begin{array}{lll}\text { 1, XXVII } & (12,62) & \text { Gaudet exercitus angelorum } \\ 4 \text {, III } & (48,11) & \text { intra in gaudium Domini tui } \\ 4, \text { XXVIII } & (48,118) & \text { alleluja } \\ 4, \text { CXXIV } & (51 / 52,184) & \text { et gloriam consequi sempiternam. }\end{array}$

Takšni pasusi nastopajo navadno na koncu motetov, včasih tudi kot interpolacije sredi skladbe, kot npr. v 1, IV $(12,16)$ »et revelabitur gloria Domini«. Redko pa najdemo exordium $\mathrm{v}$ tempus perfectumu kot $\mathrm{v} \gg$ Laetamini cum Jerusalem《 1, V $(12,19)$. V dvodelnem motetu »Audi tellus« 1 , LXVI $(24,3)$ je zaključek

${ }_{23}$ Ambros A. W., Geschichte der Musik, zv. 3, Leipzig 1881, 575 in dalje.

24 Burmeister, Musica poetica ..., 62.

25 Prim. Cvetko D., Le problème du rhythme dans les oeuvres de Jacobus Gallus, Festschrift Bruno Stäblein zum 70. Geburtstag, Kassel (etc.) 1967, 28 in dalje. 
teksta $»$ Sed tu Dominus, rector fidelium...« v tridobnem taktu, da je tako poudarjeno nasprotje teksta do prejšnjega razmišljanja o zemeljski minljivosti. Tudi tu si je vzel Gallus za vzor uglasbitev istega teksta pri Lassu (GA XV, 44), ki je prav tako komponiral isto mesto besedila v tridobnem taktu. Drugi primer, ki ga daje Burmeister za figuro hypotiposis, pa že vodi $\mathrm{k}$ melodičnim figuram: iz Lassovega moteta »Confitemini Domino« (GA VIII, 131) je navedeno mesto »laetetur cor«, katerega radostni afekt je skladatelj izrazil s številnimi koloraturami v vseh glasovih. Pri Gallusu lahko opazimo, da uporablja močno melizmatiko le zelo umerjeno, njegov stil določa $\mathrm{v}$ celoti silabična deklaracija. Brž pa ko od tega odstopa, je povod za odstopanje skoraj vselej v smislu besedila. Pokazati je mogoče več skupin tolmačenj, ki so dosežena s posebnimi melizmatičnimi tvorbami. Najprej so $\mathrm{v}$ żvezi z Burmeistrovim primerom iz Lassa izrazi radostnega afekta. Tu se nadaljuje $\mathrm{v}$ melizmatskem okrasju tradicija alelujnega jubilusa iz gregorijanskega korala. Tudi v večglasju je beseda »alleluja« tista, ki je opremljena z bogatimi koloraturami, tako npr. pri Gallusu v 2, XXX $(24,42)$, 2 , XXXVII $(24,97)$ in 2 , LXII $(30,162)$. Razen tega je tako interpretirana vrsta besedi slične razpoloženjske vsebine:

$$
\begin{array}{lll}
\text { iocundare } & 1, \text { VII } & (12,24) \\
\text { gaudere } & 4, \text { CXIII } & (51 / 52,162)
\end{array}
$$

izrazi poveličevanja:

$\begin{array}{lll}\text { laudare } & 3, \text { VIII } & (40,27) \\ \text { collaudare } & 4, \text { XXVI } & (48,110) \\ \text { laus } & 3, \text { XIX } & (40,54) \\ \text { gloria } & 1, \text { XCIV } & (24,93)\end{array}$

in končno še vsi pojmi iz območja glasbe:

$\begin{array}{llc}\text { canere } & \text { 4, VI } & (48,21) \\ \text { psallere } & 1, \text { LXXXIII, II. pars }(24,65) \\ \text { tuba } & 1, \text { XX } & (12,52) \\ \text { chorus } & 2, \text { XXX } & (30,42) \\ \text { organum } & 3, \text { XLIX } & (40,152)\end{array}$

Razen za izraz afekta lahko služijo melizmi tudi za ponazarjanje podob v samem kontekstu besedila. Predvsem pa služi melizmatika ponazarjanju gibanja nasploh. Sem spada tudi tolmačenje glasov:

$\begin{array}{lll}\text { volare } & 2, \text { LIX } & (30,154), \\ \text { currere } & 4, \text { CII } & (51 / 52,141), \\ \text { fluere } & 4, \mathrm{~V} & (48,18) .\end{array}$

Razen tega še nekateri samostalniki, ki označujejo tekočine:

$$
\begin{array}{lll}
\text { aqua } & 1, \text { XCIX } & (24,104) \\
\text { lac } & 4, \text { III } & (48,11) \text { in } 4, \text { LXIX }(51 / 52,86), \text { II. pars }
\end{array}
$$

Gibanje je prav tako značilnost živega, zato uporaba melizmatike pri:

$\begin{array}{lll}\text { vita } & 1, \text { LXXXIII } & (24,63) \\ \text { vivere } & 1, \text { CI } & (24,109), \text { II. pars. }\end{array}$


Naj navedemo še nekaj posebno lepih primerov zelo subtilnega ponazarjanja gibanja, kot npr. ponazarjanje gibov pri pisanju v 4 , XX $(48,75)$, II. pars (takt 31 in dalje):

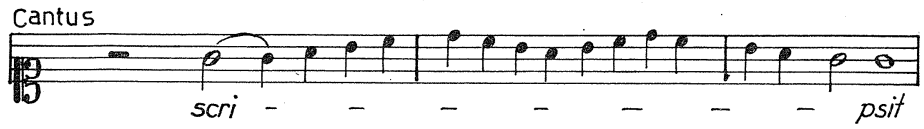

Tok solza je upodobljen v 2, III $(24,135)$ (takt 15 in dalje):

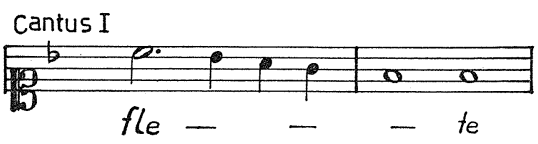

V 4, LXXVII $(51 / 52,88)$ je pri besedi »columbae« naznačeno s sočasno melizmatiko $\mathrm{v}$ gornjih glasovih utripanje golobjih peruti. Vendar pa melizmatika še ne izčrpa svoje izrazne možnosti $z$ opisovanjem zunanjega gibanja in radostnega afekta (kot notranje »razgibanosti«). Dolžina melizma ustreza v podobi izrazom dolžine, kot npr. v:

$$
\begin{array}{ll}
\text { a longe } & 1, \mathrm{I}(12,7) \\
\text { prolongatus } & 1, \mathrm{C}(24,7)
\end{array}
$$

Prav tako ustreza množina not $\mathrm{v}$ melizmu pojmom množice:

$\begin{array}{lll}\text { turba } & 4, \mathrm{LXX} & (51 / 52,72) \\ \text { manus (truma) } & 4, \mathrm{CXV} & (51 / 52,166) \\ \text { gentes } & 1, \mathrm{LX} \quad(12,169) \\ \text { multi } & 4, \mathrm{XXVI}(48,110)\end{array}$

Poseben primer figure hypotiposis so tudi tvorbe usmerjene melodike, ki jih je sicer pojmovno zajel šele leta 1650 A. Kircher v svojem delu Explicatio figurarum kot anabasis (dvigajoča se linija) in katabasis (padajoča linija), a jih je tudi tu ilustriral s primeri iz motetne literature 16 . stoletja. ${ }^{26}$ Obe figuri lahko služita ponazarjanju poteka gibanja kakor tudi upodabljanju afekta: »Anabasis, sive Ascensio est periodus harmonica, qua exaltationem, ascensionem vel res altas \& eminentes exprimimus. . « »Catabasis sive descensus periodus harmonica est, qua oppositos priori affectus pronunciamus servitutis, humilitatis, depressionis affectibus, atque infimis rebus exprimendis...«27 $\mathrm{Za}$ slikovno funkcijo teh figur naj zadoščata primera $\mathrm{V} 1$, II $(12,10)$ pri »ascendamus in montem domini« in 1 , LXVI, $(24,3)$ II. pars pri »ceciderunt... «. Sicer pa so taka mesta tako številna, da se lahko odpovemo navajanju drugih takih primerov. Opozorimo naj le še na en primer uporabe figure katabasis, ki jo najdemo v slični obliki tudi pri Lassu, Willaertu in drugih, ${ }^{28}$ na padajoče melodično gibanje za ponazoritev priklona v pozdrav, npr. $v$ »Ave Maria« $1, \operatorname{LXX}(24,20)$ (takt 1 in dalje):

${ }^{26}$ Kircher A., Musurgia universalis, Rim 1650, 145.

27 Ibid., 145. 1963,81 .

${ }_{28}$ Prim. Meier B., Wortausdeutung und Tonalität bei Orlando di Lasso, KmJb 47, 


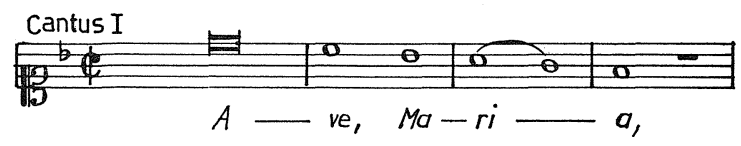

Dva primera naj ilustrirata uporabo figur katabasis in anabasis kot izraz afekta žalosti in radosti 2 , XVI $(24,175)$ (takt 9 in dalje):

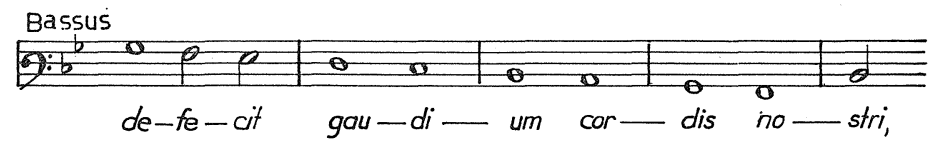

in 3 , XI $(40,35)$ (takt 1 in dalje):

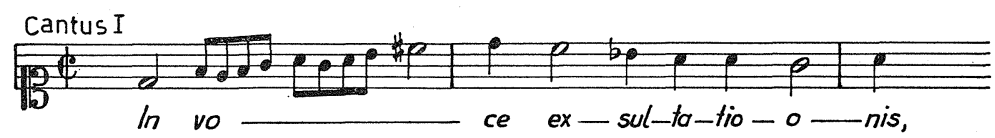

V to zvezo spadata še figuri hyperbole in hypobole, ki ju Burmeister definira kot prekoračenje glasovnega obsega. ${ }^{29}$ Burmeister jemlje svoje primere spet iz dveh Lassovih motetov, ${ }^{30} \mathrm{ki}$ pa kažeta uporabo te figure kot sredstvo za tolmačenje teksta. Pri Gallusu nastopi med drugim v 1, XVIII $(12,48)$ (takt 9 in dalje):

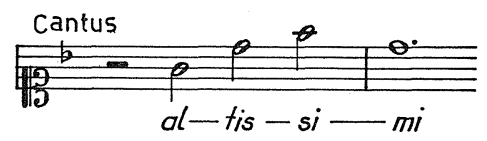

Prim. tudi 1, XXXIV $(12,91)$ pri »exaltabitur« (str. 94) v cantusu I in basu I. Figuro hypobole najdemo v 1, LXVII $(24,9)$ pri »in morte« in v 1 , XLII $(12,135)$, III. pars (takt 38):

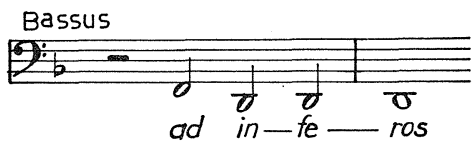

Figuro circulatio, krožno melodično gibanje, je prav tako opisal šele Kircher, ${ }^{31}$ vendar jo pogosto najdemo pri Gallusu in sploh v 16. stoletju. Na mesto »circumdederunt eum « v pasijonu $2, \mathrm{~V}(24,141)$ in na vzporedno mesto pri Lassu je opozoril že A. Schmitz. ${ }^{32}$ Razen tega je redno opremljena s to figuro beseda »coronare«, npr. v 4, XL $(48,49)$ (takt 18 in 19):

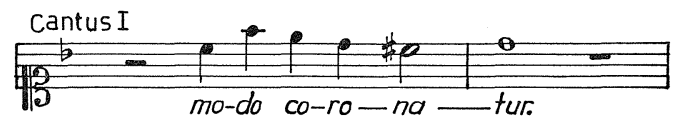

29 Burmeister, op. cit., 64.

${ }^{30}$ GA IX, 49, hypobole pri »transierunt« in hyperbole pri IX, 175 »in ore meo«.

${ }^{31}$ Op. cit., 145.

${ }^{32}$ Schmitz A., Zur motettischen Passion des 16. Jahrhunderts, v AfMw XVI, 1959, 244. 
Podobne obrate najdemo v 4 , XVII $(48,67)$ in 4, CXXV $(51 / 52,186)$. Tudi »zemeljsko obzorje« in »nebesni svod« sta ponazorjena $s$ to figuro (takt 11 in dalje):

1, XXVI $(12,61)$.

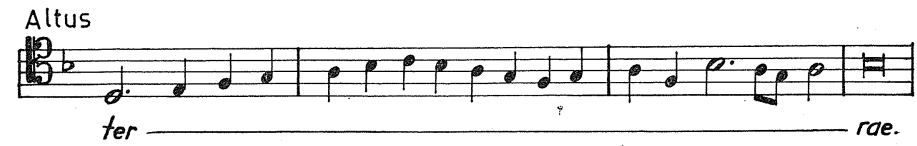

$4, \operatorname{LIX}(51 / 52,44)$ (takt 11 in 12$).$

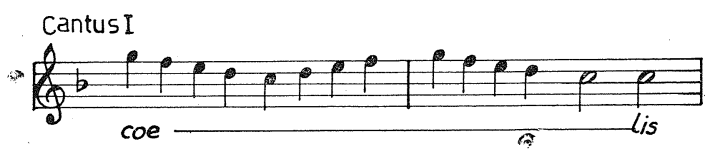

Burmeistrovi primeri kažejo, da velja oznaka pathopoeia razen za melodične tvorbe tudi za posebno melodično rabo poltonskih postopov, bodisi da so lastni tonovskemu načinu ali pa da nastanejo zaradi predznakov: »Tum quando semitonia carminis Modo congruentia saepius extra morem attinguntur. «33 Tu nastopata rada drug za drugim dva majhna sekundna intervala, kot npr. v 1, C $(24,106)$ (takt 19 in dalje):

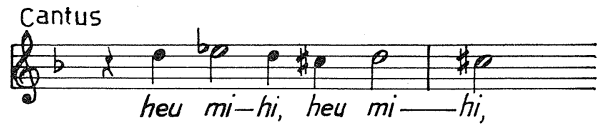

V 1, XXI $(12,54)$ je izpeljan poltonski motiv s protifugo navzgor in navzdol $\mathrm{v}$ vseh glasovih kot soggeto exordiums (takt 1 in dalje):

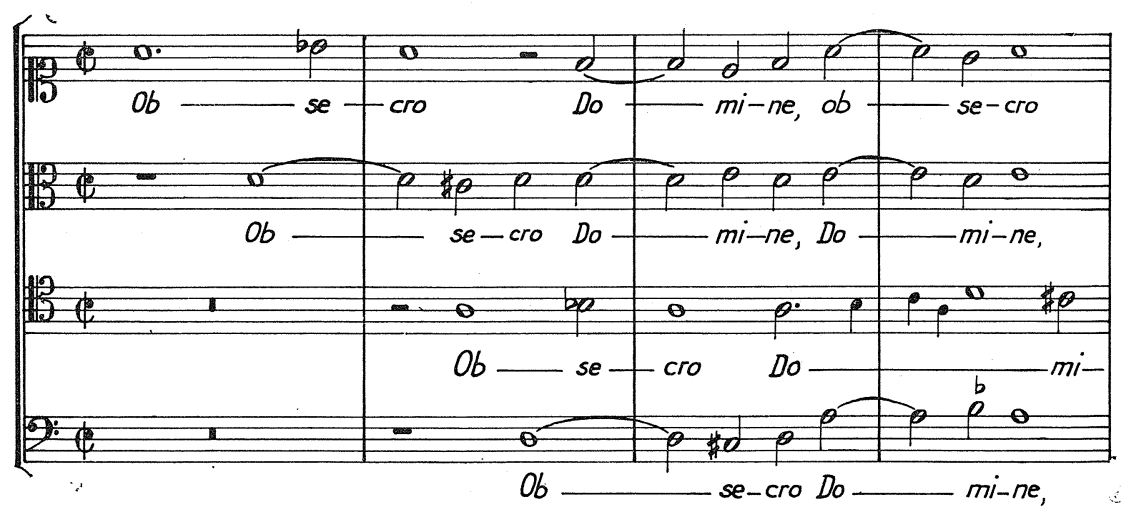

Tudi interval male terce služi izrazu afekta boli, bodisi da je že v samem tonskem načinu (takt 1 in dalje):

${ }^{33}$ Burmeister, Musica poetica, 61. 
1, LXXVIII $(24,42)$.

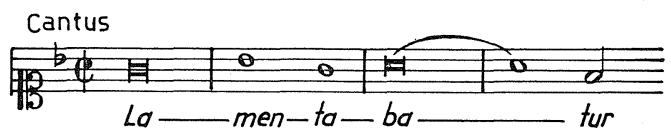

ali pa da je dosežen $\mathrm{z}$ dodatnim tonom fa fictum (takt 3):

3 , XXVIII $(40,83)$.

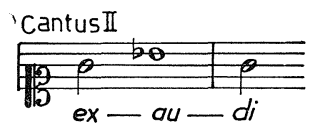

Prav tako učinkuje tudi skok male sekste navzgor kot tolmačenje teksta v smislu figure pathopoeia, ker se ta razveže s poltonskim postopom navzdol, kot npr. v 4, LXXV $(51 / 52,104)$ (takt 2 in dalje):

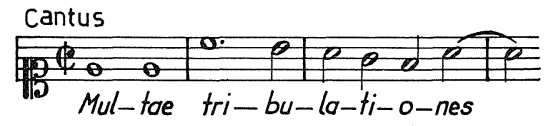

Generalno pavzo prišteva Burmeister h glasbenim figuram in jo označuje kot aposiopesis. ${ }^{34}$ Zanjo navaja tri primere iz Lassa (GA III, 192; V, 223; XV, 551), kjer pa ni notirana pavza, ampak začenja vsakikrat nov del teksta za noto brevis, ki ima fermato. Emfatični pomen fermate kakor tudi generalne pavze, ki jo je treba dostaviti, je jasen: $\mathrm{v}$ dveh primerih gre za napoved direktnega govora: »Angelus ad pastores ait: / ... ali: »Surgens Jesus dixit: / ..«. V tretjem primeru pa se zaključuje polstavek, ki je posebno pomemben, $s$ fermato: „Verbum caro factus est / et habitavit in nobis.« Podobna je uporaba generalne pavze tudi pri Gallusu: 3, LIV $(40,162)$ »Ingemuit Susanna et ait: / Angustiae...«, nadalje v 1, XXIV $(12,59)$ »Ecce, concipiês: / et paries filium...« Fermato $z$ generalno pavzo najdemo tudi $\mathrm{v}$ treh pasijonih pri besedah ${ }^{2}$ emisit ${ }^{\mathrm{*}}$ spirtum ${ }^{\prime}$ $(24,133 ; 24,153 ; 24,167)$. Tu ima generalna pavza tụdi svoj liturgični pomen: »Hic genuflectitur, et pausatur aliquantulum. «35 Tudi v sklepu vseh treh pasijonov se nahaja pri besedah »miserere nobis. Amen.« emfatična figura aposiopesis.

Končno naj še tu omenimo po Thuringusu figuro apocope: »...est, cum finalis notula prorsus auffertur, et cum nota minima cantus terminatur. «36 Ta način deklamiranja, ko se kompozicija končuje brez običajne razširitve notnih vrednosti, uporabi Gallus med drugim v 1, XXIV $(12,59)$ :

34 Ibid., 62.

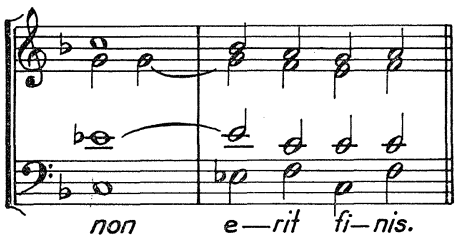

${ }_{35}$ Liber usualis Missae et Officii, Paris (etc.) (o. J.), 535.

${ }_{36}$ Thuringus J., op. cit., 127. 
Glede na tekst tu tako rekoč »manjka« zaključek dela. Podoben učinek je dosežen na koncu moteta »Beatus vir« 1 , XXXIV $(12,91)$ pri besedah »desiderium peccatorum peribit«. 37

Možnosti tolmačenja teksta niso nikakor izčrpane $\mathrm{v}$ tukaj navedenih figurah. Johannes Nucius pravi $\mathrm{v}$ uvodni pripombi $\mathrm{k}$ svojemu zelo kratkemu nauku o figurah, da bi ne bilo težko sestaviti dosti večje število figur: »Etsi ad Rhetorum imitationem non difficile erat ingentem figurarum Cathalogum coacervare, nos tamen brevitatis studio de septem sequentibus tantum agemus, ex quarum collatione, de aliis Harmoniae ornamentis facile judicabunt discentes. $3^{38} \mathrm{~V}$ zvezi $\mathrm{z}$ razlago svojih sedmih figur našteva potem veliko število besedi, »...quae ipso sono \& notarum varietate sunt exprimenda \& pingenda.«39

Obsežno raziskovanje odnosa med besedo in tonom v ustvarjalnosti Jakoba Gallusa, k čemer lahko med drugim prispeva tudi pričujoča študija, bo moralo izhajati iz nauka o figurah in $v$ zvezi $z$ besednim seznamom Nuciusa poskušati preučiti vse glasbene dimenzije glede na njih zvezo s tekstom. Pri tem bo treba tudi pokazati $\mathrm{v}$ kolikšni meri vpliva vsebina in oblika uglasbenega besedila na zborovsko zvočnost in njeno raznoliko obravnavo $\mathrm{v}$ eno in mnogozbornem stavku. Takšna raziskovanja, ki gredo prek področja nauka o figurah, so bila v zadnjem času opravljena pri dveh Gallusovih sodobnikih, pri Orlandu di Lassu in Leonhardu Lechnerju. ${ }^{40}$ Primerjava dobljenih spoznanj z rezultati enake študije pri Gallusu, mora biti tem bolj poučna, ker so, kot je znano, kompozicije obeh imenovanih skladateljev v mojstrovi zapuščini ${ }^{41}$ in ker smo zveze med deli Lassa in Gallusa lahko že tu nakazali.

\section{SUMMARY}

The present paper represents a contribution to the study of the relation between word and tone in the works of Jacob Gallus. The author bases his study on the doctrine of musical figures as it.was formulated by the theorists of the 17 th century, first of all by J. Burmeister. Since Gallus' music is intimately connected with the text, the application of this doctrine to his works yields interesting results. The figures isolated by the author from the compositions of Gallus can be divided into two groups: harmonic figures, which concern the whole structure of the composition, and melodic figures, which concern the melody itself. The first harmonic figure dealt with is the fuga realis which means the occurence of imitation. This generally used technique has an intimate connection with the text, only if it occurs in the middle of a homophonic piece. Its subsidiary form is, among other things, also hypallage, a counter-fugue serving to represent a contrast of content. In this connection it is interesting to note that Gallus follows

37 Kircher označuje isto figuro kot »repentina abruptio« in navaja isto mesto teksta kot posebno primerno za njeno uporabo (Op. cit., 145). Prim. enako obdelavo besedila pri Lassu v GA III, 56.

38 Nucius J., op. cit., pogl. VII.

39 Ibid.

${ }_{40}$ Meier B., Wortausdeutung und Tonalität ...(Prim. op. 28); isti, Alter und neuer Stil in lateinisch textierten Werken von Orlando di Lasso, AfMw XV, 1958, 151 in dalje. Weber H., Die Beziehungen zwischen Musik und Text in den lateinischen Motetten Leonhard Lechners, disertacija, Hamburg 1961.

${ }^{41}$ DTÖ, zv. 12, XXXIII. 
the model of Lasso in his motet »Peccantem me quotidie« since Lasso in his composition of the same text also used a counter-fugue. As a further means of interpreting a text, the figure noema is employed, that is, a chordal passage in an otherwise polyphonic composition. This figure in contrast to imitation which illustrates the text in an image arouses a strong emotional state which results in turning the attention of the listener to the corresponding meaning of the text. Far more often than simple noema its repetitive forms analepsis and auxesis occur. The corresponding figure in polychoral compositions is anaploce which occurs in Gallus in such a characteristic form that Gallus' works were already taken by the theorists of the early 17 th century as school examples of this polychoral technique. Among the harmonic figures in a narrower sense the dissonant figure syncope occuring in connection with the figures pleonasmus and symblema, serves for effective underlining of an emotional state. In Gallus, the employment of the double subdominant, which nearly always appears in passages of heavy emotional content, belongs to specific harmonic structures. Such an employment of the double subdominant is denoted by Burmeister as the figure pathopoeia. The figure hypotyposis may comprise interpretation of strong emotional states and may illustrate the text in various ways. So it can occur, for example, as a change of a binary to ternary metre which is induced by a joyful mood in the text. In this respect Gallus' motet »Auditellus" is interesting with its conclusion in a ternary metre. Also here, Gallus follows Lasso's composition for the same text who set to music the same passage of this text in a ternary metre. Further, the figure hypotyposis may have a melodic meaning and denotes the employment of melisma, especially of coloraturas, to the effect of underlining a special moment of the content, above all, joy. In addition, this figure serves to illustrate movement and everything that is living. Gallus made a very moderate use of melisma, but when he did employ it, the reason was nearly always provided in the contents of the text. A special example of the figure hypotyposis appears in the structure of the so-called directed melodics: anabasis - an ascending melody, and katabasis - a descending line. Both the figures are employed by Gallus to illustrate progress of movement and to depict strong emotions. These figures are similar to circulatio, that is, a circular melodic movement, often found in Gallus and other composers of the 16th century. The passage »circumderunt eum « in the Passion 2, V $(24,141)$ and the parallel passage in Lasso has already been discussed by A. Schmitz. Like hypotyposis, the figure pathopoeia also has a melodic meaning in addition to a harmonic meaning. So Burmeister denoted the special use of semi-tonal progressions as pathopoeia, whether these are a part of tonality or not. Finally the author of the paper draws attention to the fact that Gallus, like other authors of that period, employs the general rest, denoted by Burmeister as aposiopesis, as a means of emphatic stress. 